\title{
ALOJAMENTO CONJUNTO: DIFICULDADES E FACILIDADES RELATADAS PELAS MÃES DE RECÉM-NASCIDOS PREMATUROS
}

\section{ROOMING-IN: DIFFICULTIES AND FACILITIES REPORTED BY MOTHERS OF PREMATURE NEWBORNS}

\begin{abstract}
Bruna Ruiz Inácio', Bianca Machado Cruz Shibukawa'*, Maria de Fátima Lopes Merino', Marcela Demitto Furtado', leda Harumi Higarashi'

'Universidade Estadual de Maringá, Departamento de Enfermagem, Paraná, Brasil.
\end{abstract}

*Autor correspondente: Avenida Itororó, 1388. CEP: 87010-460. Telefone: (44) 99703-7149. E-mail: bih.cruuz@ gmail.com.

\section{RESUMO}

Objetivou-se identificar as facilidades e dificuldades relatas por mães de recém-nascidos prematuros/baixo peso, durante a internação em alojamento conjunto em um Hospital Universitário. A coleta de dados foi realizada com dez puérperas internadas no Alojamento Conjunto, por meio de entrevista semiestruturada. A interpretação dos dados foi realizada pela análise do conteúdo, modalidade temática, de onde emergiram quatro categorias: Apoio familiar durante internação; A volta ao lar com meu bebê; A insegurança frente ao cuidado ao recém-nascido prematuro; A importância da ajuda profissional durante o período de internação. Todos os aspectos éticos e legais previstos foram respeitados. Os resultados apontaram que as puérperas consideram de grande relevância a presença da família durante esse período, pelo apoio emocional. O desejo de retornar para casa com a criança, justificado pela vontade de apresenta-la aos entes queridos também foi destacado pelas mães, além de contar com a ajuda dos familiares no cuidado ao bebê. Outro aspecto importante, relatado por elas, foi o medo e a insegurança de retornar para casa com uma criança prematura, e não ser capaz de identificar as necessidades do recém-nascido. A assistência dos profissionais de saúde, durante o seu período de internação com o bebê, foi destacada pelas mães como de extrema importância para esclarecer dúvidas e minimizar os receios referentes ao cuidado com a criança. Desta forma, este estudo contribui para ressaltar os principais receios das mães de prematuros, os quais podem ser utilizados pelos profissionais de saúde para criar estratégias direcionadas de educação em saúde, a fim de proporcionar maior segurança ao binômio.

Descritores: Recém-nascido prematuro. Cuidado do lactente. Alojamento conjunto.

\section{ABSTRACT}

The objective was to identify the facilities and difficulties reported by mothers of premature / low birth weight infants, during hospitalization in a joint accommodation in a University Hospital. Data collection was performed with ten puerperal women admitted to the Joint Housing, through semistructured interview. Data interpretation was performed by content analysis, thematic modality, from which four categories emerged: Family support during hospitalization; The homecoming with my baby; Insecurity regarding care for premature newborns; The importance of professional help during the hospitalization period. All ethical and legal aspects provided for were respected. The 
results showed that the puerperal women consider the presence of the family during this period of great importance, due to their emotional support. The desire to return home with the child, justified by the desire to introduce her to loved ones, was also highlighted by the mothers, in addition to having the help of family members in caring for the baby. Another important aspect, reported by them, was the fear and insecurity of returning home with a premature child, and not being able to identify the newborn's needs. The assistance of health professionals, during their hospitalization period with the baby, was highlighted by the mothers as extremely important to clarify doubts and minimize the fears related to the care of the child. Thus, this study contributes to highlight the main fears of mothers of premature babies, which can be used by health professionals to create targeted health education strategies, in order to provide greater security for the binomial. Descriptors: Premature newborn. Infant Care. Rooming.

\section{INTRODUÇÃO}

O período de gestação normal, dura cerca de 40 semanas a partir da data da última menstruação (DUM) da mulher, crianças nascidas com uma idade gestacional (IG) de 20 a 37 semanas são consideradas recém-nascidas pré-termo ou também chamadas de prematuras e crianças nascidas com peso inferior a $2500 \mathrm{~g}$ são consideradas baixo peso (BARBOSA \& FUKUSATO, 2020).

A prematuridade é multifatorial, dentre as causas estão: baixa renda mensal da família, primeira gestação, ausência de acompanhamento pré-natal ou acompanhamento inadequado, sangramentos e doença hipertensiva exclusiva da gravidez (NEULS, 2019).

A fim de melhorar a assistência para esta clientela, os conhecimentos sobre a temática têm avançado cientificamente nos cuidados referentes ao recém-nascido pré-termo (RNPT), colaborando para redução da taxa de mortalidade destes, bem como tende a aumentar a sobrevida desses bebês. Contudo, o aumento da sobrevida aumenta também a probabilidade de causar sequelas permanentes na criança que, muitas vezes, podem demandar um cuidado especializado e requerem um tempo de dedicação dos pais (PASSOS et al., 2020).

Mesmo que os recém-nascidos não tenham sequelas neurológicas comprovadas, eles podem apresentar alterações no desenvolvimento, quando comparados às crianças que não nasceram prematuras. Estudo realizado comparando crianças que nasceram pré-termo com crianças que nasceram a termo mostram que elas possuem um escore menor quando são realizados testes motores, $o$ que pode influenciar o seu desempenho funcional, evidenciando um atraso no início da marcha e da capacidade de autocuidado (RODRIGUES, 2018).

Pesquisa realizada no terceiro ano de vida apontou que as crianças que nasceram prematuras começaram a andar mais tardiamente do que crianças nascidas à termo (SILVA et al., 2016). Esses acontecimentos tendem a influenciar o cuidado da criança, pois afetam diretamente as expectativas da família com relação ao bebê (BARBOSA \& FUKUSATO, 2020).

Portanto, os profissionais de saúde responsáveis pelo atendimento destes, devem primar pela humanização, atendimento o qual visa proporcionar assistência de qualidade, fazendo conexões entre os avanços tecnológicos e melhorias no cuidado ao binômio e no ambiente de trabalho para os profissionais, assim a humanização tem de ser entendida como parte fundamental da assistência (BATISTA et al., 2017). 
O cuidado humanizado deve atender todos os aspectos biopsicossociais das mães e familiares, uma vez que, a prematuridade muitas vezes implica em uma dificuldade de adaptação da criança e também dos pais. Neste cenário, os profissionais de saúde, podem estimular o uso do método Canguru como uma forma de implantar a humanização do cuidado, possibilitando a criação ou fortalecimento do vínculo entre o binômio (FERREIRA et al., 2019).

Esta forma de acompanhamento do binômio mãe-filho, no hospital, proporciona um cuidado humanizado e deve fornecer suporte e apoio às mães, incentivando-as a cooperar no cuidado com o filho, além de fortalecer a sua independência do serviço de saúde, na assistência ao filho. Assim, acredita-se que após a alta do bebê, os pais estarão preparados e seguros para prestarem o cuidado no domicilio, assumindo esta responsabilidade (FERREIRA et al., 2019, KOPP et al., 2020).

O trabalho junto à estas mães, neste período de permanência no hospital, são determinantes do cuidado que será ofertado ao bebê. As orientações sobre cuidados com o bebê, os problemas com a amamentação, higienização e administração de medicamentos, entre outros, deverão ser reforçadas diariamente pela equipe, até que as mães se sintam capazes de ofertar esta assistência com segurança (CHAGAS et al., 2017).

A presença afetiva da equipe de enfermagem para com a família, disposta a escutar e esclarecer todas as suas dúvidas, deve ser considerada tão importante quanto os procedimentos técnicos realizados junto ao bebê neste período (BATISTA et al., 2017). Considera-se que este processo de permanência no hospital, envolve momentos de grande tensão para a mãe, e os resultados das ações nem sempre se desenrolam como o esperado, o vínculo entre mãe e filho deve ser continuamente estimulado e a enfermagem destaca-se como a principal responsável por integrar os pais no cuidado ao filho. Portanto, no planejamento das ações junto ao RN, os pais devem ser considerados como parte indissociável do processo, portanto, deve-se direcionar tanta atenção para estes quanto o bebê (PILECCO \& BACKERS, 2020).

Diante destas questões delimitou-se como objetivo da pesquisa, identificar as facilidades e dificuldades relatas pelas mães de recém-nascidos prematuros, durante a internação em alojamento conjunto.

\section{MÉTODO}

Trata de um estudo exploratório, descritivo, de natureza qualitativa, realizado na enfermaria conjunta de um Hospital Universitário Regional do noroeste do Paraná, no período de junho a agosto de 2014.

O hospital conta com uma Enfermaria Conjunta com três leitos, denominada Enfermaria Canguru, situada na Unidade de Internação Pediátrica, destinada a recém-nascidos advindos da UTI Neonatal, que necessitam de cuidados específicos, destacando-se o ganho de peso e a boa pega e sucção ao seio materno, e onde são realizadas orientações sobre os cuidados com as crianças durante a internação e após a alta hospitalar, como posições para amamentar, pega correta e ordenha.

O hospital conta ainda com um banco de leite humano, o qual presta apoio e ações de educação em serviço para atualização constante dos profissionais, para que estes estejam sempre habilitados a orientar as mães acerca da amamentação. 
Para a implementação deste estudo, foram realizadas entrevistas com dez mães de bebês prematuros, internados no referido setor. Os critérios de inclusão foram, binômios cujo bebê nasceu prematuro ( $<37$ semanas) e/ou baixo peso ( $<2.500$ gramas), internados a um período igual ou superior a cinco dias, visto que o período padrão de alta hospitalar para bebês a termo é de dois dias, porém como os bebês são prematuros, optou-se por conceder três dias a mais para adaptação da mãe com o bebê, para que esta pudesse dividir suas principais dificuldades e facilidades. Foram excluídos aqueles binômios que não aceitaram participar da pesquisa.

A coleta de dados foi realizada por meio da utilização de um roteiro semiestruturado, contendo caracterização dos sujeitos e uma segunda parte, contemplando a abordagem da temática central do estudo, a partir da seguinte questão norteadora: Quais as dificuldades enfrentadas pelas mães durante o período de internação do RN e quais as expectativas e facilidades para o cuidado do bebê após a alta hospitalar?

Após o consentimento dos sujeitos, mediante assinatura em Termo de Consentimento Livre e Esclarecido (TCLE), as entrevistas foram gravadas e transcritas na íntegra. Os dados coletados passaram por processo analítico e descritivo a partir do referencial de análise de conteúdo, que consiste em três etapas: pré-análise, exploração dos dados, tratamento das informações obtidas e interpretação (BARDIN, 2011).

Na pré-análise, as entrevistas foram transcritas na íntegra e depois realizadas diversas leituras. Em seguida, realizou-se um mapeamento das falas, a fim de facilitar a visualização do material como um todo. Na última etapa, foram identificadas unidades de registro e recortes necessários para compreender as informações contidas nos relatos e estabelecer as unidades de categorias do estudo. Os dados quantitativos foram discutidos descritivamente e a distribuição dos mesmos ocorreu por meio de frequência absoluta e percentual.

A fim de assegurar o anonimato da participação do estudo, os sujeitos foram identificados pela expressão "MÃE" seguidas do numeral pertinente à ordem de realização das entrevistas. Será mantido absoluto sigilo dos dados de identificação dos sujeitos da pesquisa e os resultados obtidos serão utilizados unicamente com finalidade científica, podendo ser publicados em eventos ou periódicos da área de saúde.

O projeto da pesquisa foi submetido à apreciação da Comissão de Regulamentação das Atividades Acadêmicas (COREA) do hospital em questão, e após sua aprovação foi encaminhado ao Comitê Permanente de Ética em Pesquisa com Seres Humanos - (COPEP), por meio da Plataforma Brasil (Parecer 744.552), foi aplicado o Termo de Consentimento e Assentimento Livre e Esclarecido, além de este estudo ser realizado de acordo com todas as diretrizes estabelecidas pela norma ética vigente, conforme Resolução 466/12 do Conselho Nacional de Saúde (CNS).

\section{RESULTADOS}

Foram entrevistadas dez mulheres internadas na Enfermaria Canguru. A idade das mães variou entre 16 e 38 anos, sendo a média 23 anos. O nível de escolaridade das mães foi, ensino fundamental incompleto $10 \%(n=1)$, ensino fundamental completo $60 \%(n=6)$ e, ensino médio completo $30 \%(n=3)$. Quanto ao estado civil, oito mães eram casadas e duas não tinham companheiro. Quanto à ocupação, $40 \%$ trabalhavam e $60 \%$ eram do lar e, a religião que prevaleceu foi a católica (60\%). Duas mães eram adolescentes com menos de 18 anos, solteiras e não tinham companheiro. 
Com relação à abordagem da temática central do estudo, os relatos das participantes permitiram a configuração de quatro categorias, que serão discutidas na sequência.

\section{O APOIO FAMILIAR DURANTE A INTERNAÇÃO}

Durante a internação na Enfermaria Canguru, onde foi realizada a pesquisa, não é permitida a presença constante de um acompanhante para a mãe e o RN em função da própria característica física da unidade. A presença de alguém da família como acompanhante, só é possível durante o horário de visitas, que acontece uma vez por dia.

Os familiares que mais visitaram as puérperas no período foram os maridos e as mães. Também foram citados o pai, avó e prima. As falas das entrevistadas, deixa transparecer a importância que elas dão à presença das visitas, principalmente da mãe durante o internamento:

(...) me sinto sozinha, pois na GO eu tinha como ficar com um acompanhante, minha mãe ficava lá comigo, aqui eu fico sozinha. (MÃE 9)

(...) mesmo recebendo visitas, ainda me sinto sozinha. (MÃE 8)

Não foi evidenciada neste estudo, a visita de pessoas que não fossem familiares das mulheres internadas. A maior parte delas (90\%) referiu receber visita de algum familiar

(...) meu pai vem bastante me visitar, meu marido também. (MÃE 1)

(...) meu marido e a minha mãe vêm bastante me visitar. (MÃE 3)

(...) a minha mãe vem todo dia me ver. (MÃE 4)

Uma das adolescentes participantes da pesquisa, mãe de gêmeos, referiu receber a visita de familiares, fazendo referência principalmente ao pai. Quando questionada sobre as visitas no hospital, ela mencionou o pai, a mãe e a tia, não mencionando o pai das crianças ou algum outro companheiro.

Eu recebo visitas aqui do meu pai, minha mãe e minha tia, mas é o meu pai que vem mais. (MÃE 10)

\section{A VOLTA AO LAR COM MEU BEBÊ}

O fato mais citado entre as participantes da pesquisa foi o desejo de voltar para casa com o seu filho (80\%). A justificativa dessas mães é poder apresentar o bebê para a família e principalmente o fato de que em casa, ela acredita que terá alguém para auxiliá-la no cuidado, acreditando que a responsabilidade pelo filho poderá ser dividida com algum familiar.

Das entrevistadas, sete relataram que receberiam ajuda de algum familiar para cuidar da sua criança. Destas, cinco seriam auxiliadas pela mãe e duas pelo marido. As demais mães não se manifestaram quanto a esta questão.

(...) sim, porque em casa eu vou ter a ajuda da minha mãe da minha família, né? (MÃE 2)

(...) Porque em casa eu tenho o meu esposo, lá ele vai me ajudar, porque aqui eu estou sozinha. (MÃE 1)

(...) Ai, eu quero ir embora logo, para cuidar dele em casa, porque lá a minha mãe vai ficar comigo. (MÃE 10) 
As mães relataram ainda, que em casa elas acreditam que conseguiriam cuidar melhor do seu filho, se sentindo mais livres e seguras. Esta exposição dos sentimentos de duas das mães, ocorre pela percepção de que o período de internação, para elas, estava sendo muito estressante.

(...) é por eu estar aqui todo o tempo eu não estou conseguindo descansar. Antes eu sabia que estava difícil, mas pelo menos um pouco eu descansava, mas agora por ter que ficar aqui todo o tempo... e agora eu não consigo mais descansar, porque de manhã que ele dorme eu não consigo descansar porque o povo entra, ai de noite que ninguém entra ele não dorme. (MÃE 1).

O fato de eu ter medo de deixa-lo sozinho (enfermaria), pois não tem ninguém para ajudar aqui. Até tenho que tomar banho rápido, porque não sei o que está acontecendo lá fora com o bebê. (MÃE 9)

Outro aspecto da ansiedade pelo retorno ao lar de algumas mães é o fato de terem outros filhos em casa, aos cuidados de terceiros. Duas mães destacaram esta situação como preocupante durante o período de internação.

O fato de ter que dormir aqui dificultou, pois eu tenho outro filho (...). (MÃE 7)

Quero ir embora logo para ficar junto com meu outro filho. (MÃE 5)

\section{A INSEGURANÇA DA MÃE NO CUIDADO AO RECÉM-NASCIDO PREMATURO}

A insegurança da mãe referentes ao cuidado com o bebê, tanto no hospital quanto no retorno ao lar é evidenciado neste estudo quando, apesar do longo tempo de internação e das orientações recebidas dos profissionais, elas ainda não se sentem aptas para prestar os cuidados necessários ao bebê:

Fiquei muito tempo internada, mas ainda não estou preparada (para cuidar do bebê). (MÃE 10) (...)Eu tenho medo de não conseguir cuidar dele, de acontecer alguma coisa... eu por exemplo, eu acabar me esgotando tanto, passar mal e não poder ficar aqui... se eu passo mal, como fica ... Então esse é o meu medo, chegar a esgotar tanto, me sentir tão cansada, passar mal e não conseguir ficar aqui. (MÃE 1)

\section{A IMPORTÂNCIA DA AJUDA PROFISSIONAL DURANTE O PERÍODO DE INTERNAÇÃO}

O estudo demonstra a satisfação das mães com relação a ajuda multiprofissional recebida durante o período de internação. Elas destacaram o apoio de enfermeiros, médicos, fonoaudiólogo, profissionais do banco de leite do hospital e da psicologia. Dentre todos os citados, as equipes que mais se destacam foram a enfermagem e fonoaudiologia.

(...) vem um monte de gente me visitar (profissionais). Enfermeiro, fono, pediatra, que me ajudaram na hora de amamentar meu filho. (MÃE 3)

Recebi orientações da fono desde quando ela nasceu, porque ela é prematura e teve um pouco de dificuldade. (MÃE 6)

Embora algumas mães, relatem medo, angustia, cansaço em cuidar do filho, percebe-se nas falas, que elas ressaltam significativamente a atuação das equipes multiprofissionais que atuam juntamente a elas e ao bebê, tentando transmitir maior conhecimento e segurança em procedimentos relativos ao cuidado do bebê, que poderá ser utilizado no retorno ao lar. 
Eu acho que como a gente recebe muita gente para ajudar, a gente perde o medo. (MÃE 3)

Aqui eu aprendi a dar banho e a cuidar do meu filho, melhor do que eu já sabia. (MÃE 4)

Está sendo bom (internação)pois estou aprendendo a cuidar bem do meu filho. (MÃE 9)

A enfermagem está presente nas falas das entrevistadas quando elas se referem aos momentos de importância significativa para as mães, como a hora da amamentação e hora do banho.

As enfermeiras e o pessoal me ajudaram bastante (...) (MÃE 2)

Antes eu tinha (medo). Agora eu não tenho mais porque as enfermeiras me ensinaram bastante (...) (MÃE 3)

\section{DISCUSSÃO}

O momento da visita para as pessoas que estão internadas, é uma ocasião aguardada, pois é no horário das visitas que as pessoas podem dividir com alguém os seus medos e angústias, além do fato de que a presença de um ente querido proporciona momentos de prazer, fazendo-os esquecer por alguns instantes as preocupações decorrentes do período de internação (BÉLANGER et al., 2017).

O convívio da família com o recém-nascido internado, precisa ser estimulado, uma vez que proporcionar estes momentos de convívio familiar pode favorecer a recuperação, bem como aliviar o estresse (AMARAL \& CALEGARI, 2016, FELICIANO \& CARDOSO, 2017).

O alojamento conjunto não é uma tarefa fácil para as mães, uma vez que, quando os bebês se tornam pacientes, elas são as acompanhantes dos filhos, e por estarem também em processo de recuperação do pós parto, encontram-se fragilizadas e com necessidade de cuidados. Nesta perspectiva, as novas mães precisam tomar todos os cuidados com a própria saúde, e ainda promover os cuidados com o bebê, sobrecarregando as mães (ROLIM et al., 2017).

Neste cenário, a fragilidade emocional é inerente ao processo de maternidade, visto que estas se encontram sozinhas para prestar os cuidados para o recém-nascido, além de estarem no período de puerpério imediato, fator o qual por si só, já exige uma série de cuidados. Portanto, o apoio da equipe de saúde, bem como a permissão de acompanhantes e visitas, é essencial neste novo processo da vida feminina (ROLIM et al., 2017, ALMEIDA et al., 2018).

Outro fator que necessita da atenção dos profissionais de saúde, é a frustação materna, uma vez que durante o período gestacional, há a criação no imaginário de um bebê que nasça grande, forte e saudável e quando isso não ocorre, gera um sentimento de frustração na mulher, o que somado ao fato de ficar sozinha com o bebê hospitalizado, gera sentimentos de medo, ansiedade, depressão e até mesmo quadros de negação (BASEGGIO et al., 2017)

Isso evidencia a importância para a puérpera da presença do familiar tanto após o parto quanto o acompanhamento durante o período pré-natal. Para elas, esta presença durante este processo, fornece segurança e a possibilidade de esclarecimentos pertinentes ao cuidado, a serem realizados com RN (BÉLANGER et al., 2017).

Por isso, enfatiza-se a necessidade de estimular a aproximação familiar nestes cenários, uma vez que na maioria das vezes, as puérperas encontram apoio em pessoas que tenham laços consanguíneos, ou com seus companheiros (PRATES et al., 2016). A aproximação familiar também deve ser estimulada para criar um senso de responsabilidade coletiva para com o bebê, uma vez que ao receber alta, o binômio precisará contar com uma rede de apoio (FELICIANO \& CARDOSO, 2017, ROLIM et al., 2017). 
A alta hospitalar apesar de esperada, é geradora de medo e ansiedade nas mães, as quais se encontram em um ambiente hospitalar, rodeada de profissionais de saúde. Ao ir para a casa, há um misto de sentimentos de alegria e medo, e cabe aos profissionais de saúde a promoção de educação em saúde acerca dos cuidados neonatais para auxiliar na construção da confiança materna e familiar (PORTO \& PINTO, 2019).

Quando o binômio chega em casa, os principais auxiliares na rede de apoio, geralmente são as mulheres mais velhas daquela família, como mães e avós, pois no nascimento de um filho, nasce também uma mãe, a qual terá como inspiração àquelas que possuem em seu convívio, confiando a estas mulheres os cuidados iniciais com seus filhos (ZANATA \& ARPINI, 2017, SOUZA \& LEMOS, 2018, RODRIGUES \& SCHAEFER, 2019).

Outra questão geradora de medo e ansiedade na puérpera é mudança da dinâmica familiar previamente estabelecida, a existência de outros filhos os quais, antes possuíam a atenção integral da mãe, agora terão que dividir não só a atenção familiar, mas também participar dos cuidados do mais novo membro da família. Esta reorganização na dinâmica domiciliar, precisa ser prevista e planejada, a fim de atribuir segurança aos cuidados que serão prestados ao bebê (RODRIGUES \& SCHAEFER, 2019).

Preparar e instrumentar as mãe para o cuidado da criança prematura é fundamental para o sucesso da adaptação do cuidado, uma vez que a criança prematura é vista pelas mães como alguém frágil, pequeno, muito susceptível à intercorrências, o que faz com que elas procurem sempre os aspectos negativos presentes na criança ou seja, a percepção da evolução que a criança apresenta com o tempo, conforme seu crescimento, é vista de maneira diferente pela mãe, uma vez que o bebê sempre será visto por ela como alguém indefeso (BASEGGIO et al., 2017).

Esta visão relativa ao seu filho, quando não trabalhada, pode gerar sentimento de medo e incapacidade para o cuidado do seu filho. Essas angústias são comuns no período do puerpério devido a mudança emocional, porém provisória, que faz com que a mulher esteja mais frágil psiquicamente, contudo mesmo que os sintomas depressivos possam ser comuns, é preciso ficar atento para que a mulher não desenvolva um quadro de depressão patológica (SOUZA \& LEMOS, 2018, PORTO \& PINTO, 2019, RODRIGUES \& SCHAEFER, 2019).

Portanto, o auxílio multiprofissional é essencial para atender todos os aspectos biopsicossociais desta puérpera. Neste trabalho, os resultados apontaram o apoio multiprofissional como benéfico para o binômio. O trabalho do fonoaudiólogo destaca-se neste grupo de pacientes, pela relevância do aleitamento materno para o RN prematuro. Na maioria dos casos é ele que fornece a ajuda à mãe e à criança quando esta apresenta alguma dificuldade no momento da amamentação. Seu papel objetiva atender à necessidade de pega, favorecendo assim, uma alta hospitalar mais rápida, tornando este momento um ato prazeroso para ambos (SOARES et al., 2016).

Salienta-se ainda que, o fato dele estar presente na maioria das vezes em que a criança está aprendendo o ato de pega e sucção, o torna um profissional muito vinculado à puérpera, pois o ato de amamentar é um dos momentos mais esperados quando se gesta uma criança. Além disso, esse profissional está interligado com vários outros aspectos como: contato mãe/bebê, comunicação verbal/não verbal entre o binômio e desenvolvimento da audição e linguagem (SOARES et al., 2016).

A equipe multiprofissional é de suma importância para amenizar o cenário da prematuridade, onde a família está passando por um processo de adaptação ao novo integrante da sua família, 
portanto o olhar multidisciplinar sobre a família trás diversos benefícios ao englobar todos os aspectos biopsicossociais do binômio.

Muitas mães não têm afinidade com os cuidados ao bebê e desenvolvem algumas habilidades, como por exemplo o banho, nesse período de internação. Portanto é essencial o amparo profissional para o desenvolvimento de habilidades do cuidado, o que aponta para a equipe de enfermagem, a qual geralmente, possui facilidade maior do que outros profissionais para perceber as dificuldades de desenvolver os cuidados ao bebê devido seu contato constante com seus pacientes (SANTOS et al., 2019).

Quando é estabelecida uma boa relação entre puérpera e enfermeiro, o profissional sente-se à vontade para interferir nos cuidados, quando achar necessário, visando sempre uma recuperação mais rápida da mãe e da criança. Assim, a enfermagem durante o momento em que presta os seus cuidados, transcende a barreira da capacidade profissional e técnica e ressalta o seu papel de educador (SOARES et al., 2016, ROLIM et al., 2017).

\section{CONSIDERAÇÕES FINAIS}

O presente estudo demonstrou que a maior dificuldade encontrada pelas puérperas internadas na Enfermaria Canguru é lidar com os sentimentos de solidão e ansiedade durante a internação. A volta ao lar com os bebês é o momento mais esperado por elas. A maior parte acredita que receberá ajuda de membros da família no cuidado com a criança e que em casa conseguirá descansar mais, o que não ocorre adequadamente no período de hospitalização em parte pela dinâmica de trabalho dos profissionais.

Os atendimentos dos profissionais ao recém-nascido, são pontuados positivamente pelas mães, porém apresentam-se fragilizadas pela condição de internamento junto ao bebê. Diante disso, torna-se fundamental destacar a importância dos profissionais de saúde no acolhimento do binômio, portanto, pesquisas nesta área devem ser incentivadas, visto que o fomento na pesquisa incentiva mudanças práticas, as quais podem atender as necessidades do binômio durante sua permanência na unidade de internação.

Em especial, devemos destacar o papel da enfermagem neste contexto visto que, por ser o profissional que permanece o maior tempo junto às mães, até que estas possam retornar ao lar, ele apresenta maiores condições de oferecer um atendimento humanizado à essas mulheres.

As limitações deste estudo, referem-se ao curto tempo de coleta, que foram de três meses, visto que a enfermaria em questão contava com apenas três leitos, limitando o número amostral, contudo reintegra-se que todos os binôminos que atendiam os critérios de elegibilidade foram inclusos.

\section{REFERÊNCIAS}

ALMEIDA, C. R.; MORAIS, A.C.; LIMA, K. D. F.; SILVA, A. C. O. C. Cotidiano de mães acompanhantes na unidade de terapia intensiva neonatal. Revista de enfermagem UFPE on line, Recife, v. 12, n. 7 , p. 1949-56. 2018.

AMARAL, L. F. P.; CALEGARI, T. Humanização da assistência de enfermagem à família na unidade de terapia intensiva pediátrica. Cogitare Enfermagem, Curitiba, v. 21, n. 3, p. 1-9. 2016. 
BARBOSA, E. A.; FUKUSATO, P. C. S. Manual prático do desenvolvimento infantil. Rio de Janeiro: Thiemi Revinter. 2020.

BARDIN, L. Análise de conteúdo. Tradução de Luís Antero Reto e Augusto Pinheiro. Lisboa: Edições 70, 2011.

BASEGGIO, D. B.; DIAS, M. P. S.; BRUSQUE, S. R.; DONELLI, T. M. S.; MENDES, P. Vivências de mães e bebês prematuros durante a internação neonatal. Temas em Psicologia, Ribeirão Preto, v. 25, n. 1, p. 153-167. 2017.

BATISTA, A. P.; ALENDE, L. P.; CREMONESE, L.; SCARTON, J.; NEUMAIER, C. A.; RESSEL, L. B. Humanização do parto: significados e percepções de enfermeiras. Escola de Enfermagem Anna Nery, Rio de Janeiro, v. 21, n. 4, p. e20160366. 2017.

BÉLANGER, L.; BUSSIEÈRES, S.; RAINVILLE, F.; COULOMBE, M.; DESMARTIS, M. Hospital visiting policies impacts on patients, families and staff: A review of the literature to inform decision making. Journal of Hospital Administration, Canadá, v. 6, n. 6, p. 1-12. 2017.

CHAGAS, M. A.; ALMEIDA, N. M. S.; COSTA, M. M. L.; BASTOS, L. P. Percepção das mães acerca da vivência do método canguru. C\&D-Revista Eletrônica da FAINOR, Vitória da Conquista, v. 10, n. 3 , p. 424-35. 2017.

FELICIANO, J. R.; CARDOSO, A. L. A necessidade de formação do enfermeiro para uma relação efetiva com o acompanhante do paciente hospitalizado. Revista Uningá, Maringá, v. 54, n. 1. P. 108-118. 2017.

FERREIRA, D. O.; SILVA, M. P. C.; GALON, T.; GOULART, B. F.; AMARAL, J. B.; CONTIM, D. Método canguru: percepções sobre o conhecimento, potencialidades e barreiras entre enfermeiras. Escola de Enfermagem Anna Nery. Rio de Janeiro, v. 23, n. 4, p. e20190100. 2019.

KOPP, D. D.; ASSUMPÇÃO, P. K.; DONADUZZI, D. S. S.; SCHUTZ, T. C.; FETTERMANN, F. A. Family adhesion to the kangaroo method: the importance of the nursing team. Research, Society and Development, Vargem Grande Paulista, v. 9, n. 8, p. e437985849. 2020.

NEULS, C. S. Risk factors interference on low weight pregnancy pregnancy in a maternity of GoldenMS. Brazilian Journal of Develop, São José dos Pinhais, v. 5, n. 10, p. 17600-27. 2019.

PASSOS, S. R.; GAIS, V. R. S.; KEGLER, J. J.; BIGOLIN, L. J.; CORDEIRO, D.; TATSCH, E. N. Characterization of children with special health care needs and caregivers in a teaching hospital. Ciência, Cuidado e Saúde, Maringá, v. 19, n. e46724. 2020.

PILECCO, J. C.; BACKES, D. S. Mother-baby binding in a Neonatal Intensive Care Unit: Interactive Care Technology. Research, Society and Development, Vargem Grande Paulista, v. 9, n. 8, p. e198985610. 2020.

PORTO, M. A.; PINTO, M. J. C. Prematuridade e vínculo mãe-bebê: uma análise em UTI neonatal. Perspectiva em Psicologia, Porto Alegre, v. 23, n. 1, p. 139-51. 2019.

PRATES, L. A.; POSSATI, A. B.; TIMM, M. S.; CREMONESE, L.; SCARTON, J.; RESSEL, L. B. Care rituals operated by families during the gestational process: an ethnographic study. Online Brazilian Journal of Nursing, Niterói, v. 15, n. 1, p. 509-11. 2016

RODRIGUES, L. G. C.; SCHAEFER, M. P. Repercussões de desencontros e ambiente familiar na relação mãe-bebê: experenciando o método Bick de observação. Psicologia Clínica, Rio de Janeiro, v. 31, n. 3, p. 481-96. 2019. 
RODRIGUES, J. C. L. Desenvolvimento inicial de bebês nascidos pré-termo de alto risco neonatal em comparação a bebês nascidos a termo. 2018. 148f. Dissertação (Mestrado em Ciências) Universidade de São Paulo, Ribeirão Preto, 2018.

ROLIM, K. M. C.; SANTOS, M. S. N.; MAGALHÃES, F. J.; FROTTA, M. A.; FERNANDES, H. I. V. M.; SANTOS, Z. M. S. A. et al. O uso de tecnologia leve na promoção da relação enfermeira e pais na UTI neonatal. CIAIQ, Portugal, v. 2, n. 1, p. 1-10. 2017.

SANTOS, A.; RODRIGUES, L.; DA SILVA, W. C.; BRITO, L. L.; VIANA, M. C.; CHAVES, E. M. Educação em saúde na Unidade de terapia Intensiva Neonatal. Revista Enfermagem Atual Inderme, Rio de Janeiro, v. 48, n. 27, p. 1-9. 2019.

SILVA, J. K. M.; SARGI, A.M.; ANDRADE, I. C. O.; ARAÚJO, C. C.; ANTONIO, T. D. Motor development of preterm and term infants in the fundamental movement phase: a cross-sectional study. Fisioterapia em Movimento, Curitiba, v. 29, n. 3, p. 581-88. 2016.

SOARES, J. P. O.; NOVAES, L. F. G.; ARAUJO, C. M. T.; VIEIRA, A. C. C. Natural breastfeeding of preterm newborns from the perspective of the mother: an integrative review. Revista CEFAC, São Paulo, v. 18, n. 1, p. 232-41. 2016.

SOUZA, J. C.; LEMOS, M. F. Observação da relação mãe-bebê nos primeiros meses de vida. Perspectiva em Psicologia, Porto Alegre, v. 22, n. 1, p. 18-37. 2018.

ZANATTA, E.; ARPINI, D. M. Conhecendo a imagem, o papel e a relação avó-neto: a perspectiva de avós maternas. Estudos e Pesquisas em Psicologia, Rio de Janeiro, v. 17, n. 1, p. 343-63. 2017. 